\title{
Uretroplastia con mucosa oral en estenosis de uretra anterior
}

\author{
Roca Edreira A, Aguilera Tubet C, García-Montesinos Perea BM, García Montesinos M, \\ Hernández Rodríguez R.
}

Hospital Universitario Marqués de Valdecilla. Clínica Mompía, Santander (Cantabria).

Actas Urol Esp. 2008;32(5):517-521

\section{RESUMEN}

\section{URETROPLASTIA CON MUCOSA ORAL EN ESTENOSIS DE URETRA ANTERIOR}

Los injertos de mucosa oral pueden ser utilizados para la reparación satisfactoria de estenosis de uretra péndula y bulbar.

Material y métodos: Presentamos nuestra experiencia con injertos de mucosa oral en 8 pacientes. La longitud del injerto fue entre 4 y $16 \mathrm{~cm}$. Se han realizado tres uretroplastias en uretra péndula, dos en uretra bulbar y tres panuretrales. El seguimiento ha sido entre 36 y 60 meses.

Resultados: No se han observado recurrencias. Un paciente refirió parestesias en el labio inferior durante seis meses.

Palabras clave: Uretra. Estenosis. Mucosa oral.

\section{ABSTRACT \\ BUCCAL MUCOSA URETHROPLASTY IN ANTERIOR URETHRAL STRICTURES}

Buccal mucosal graft can be used for succesfull repair in both pendulous and bulbar strictures.

Material and methods: We present our experience with buccal mucosal graft repair in 8 patients with onlay patch that varies from 4 to $16 \mathrm{~cm}$. in length. Three pendulous, two bulbar and three panurethral strictures were repaired. These patients were observed for 36 to 60 months.

Results: No stricture recurrences were observed. Only one patient had lower lip paresthesia for six months.

Keywords: Urethra. Stricture. Buccal mucosa.

$\mathrm{L}^{2+n^{2}}$ as técnicas de uretroplastia han evolucionado mucho en los últimos tiempos, debido a los cambios experimentados en la etiología de las estenosis y en las técnicas de transferencia tisular. La utilización de injertos de mucosa oral para estenosis, tanto de uretra péndula como bulbar, está ganando adeptos en los últimos años debido a sus buenos resultados.

\section{MATERIAL Y MÉTODOS}

Presentamos 8 pacientes diagnosticados de estenosis de uretra y tratados mediante uretroplastia con mucosa bucal entre el año 2002 y 2004 con un seguimiento mínimo de 3 años. La edad de nuestros pacientes estaba comprendida entre los 47 y 72 años. La etiología de la estenosis fue traumática inicialmen- te y tratada posteriormente con dilataciones durante años en dos casos, un caso secundario a resección transuretral de próstata, y el resto desconocida, por ser pacientes con historia de muchos años de dilataciones periódicas y uretrotomías internas. La localización de la estenosis fue en uretra péndula en tres casos, uretra bulbar en dos, y panuretral en tres casos. La longitud de las estenosis fue entre 4 y 16 $\mathrm{cm}$. A todos los pacientes se les solicitó uretrografía retrógrada y miccional previa a la cirugía (Fig. 1).

En los 8 casos se realizó uretroplastia con mucosa bucal en un tiempo, obteniendo el injerto de labio inferior, o labio inferior y ambas mejillas, en función de la longitud de la estenosis (Figs. 2 y 3). En las estenosis de uretra péndula, el injerto fue colocado en posición dorsal sobre cuerpos cavernosos (Fig. 4). 


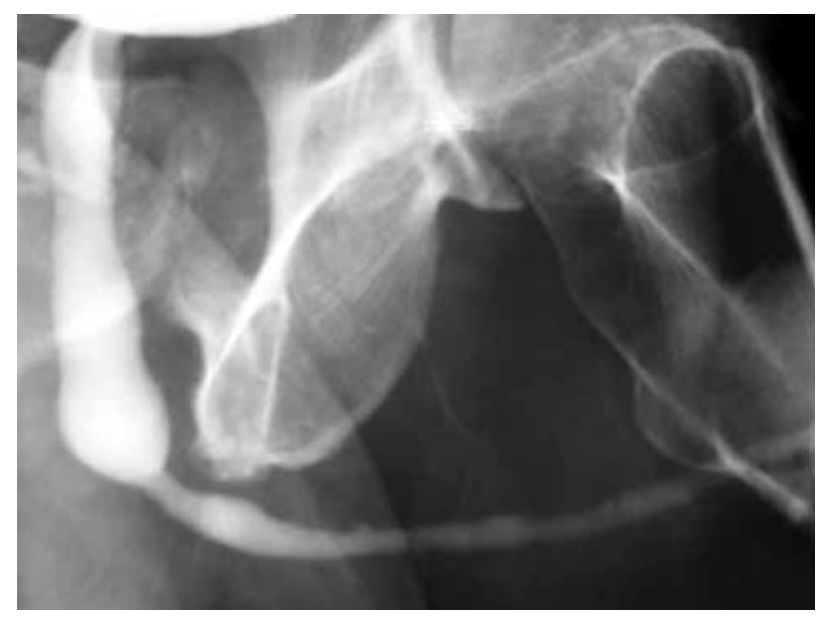

FIGURA 1. Uretrografia.

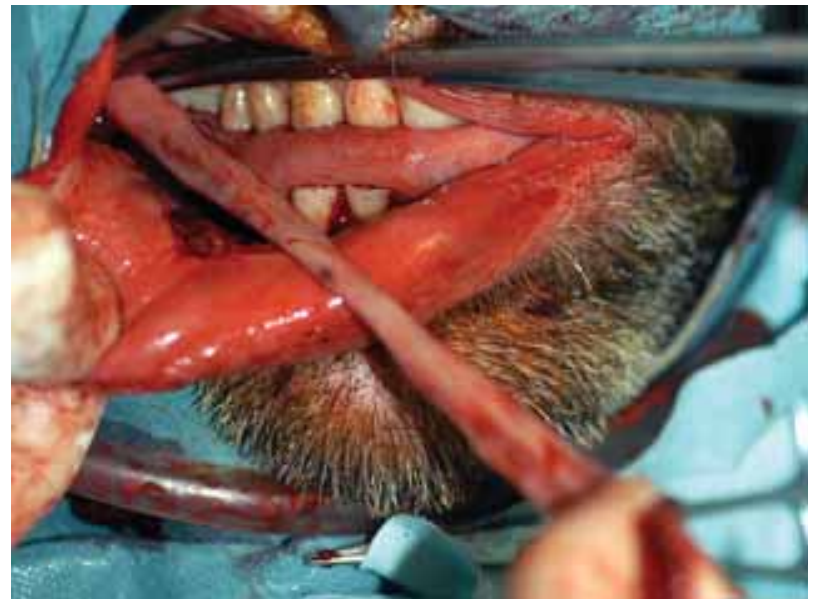

FIGURA 2. Obtención del injerto.

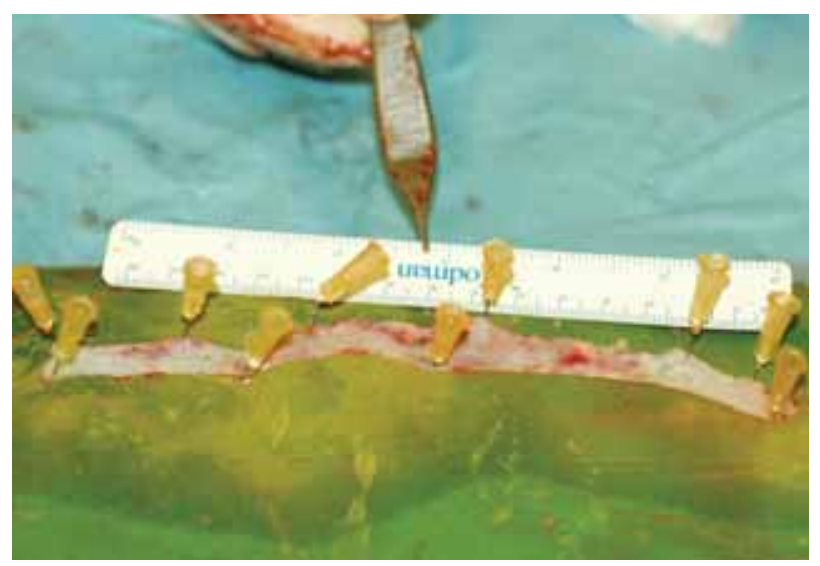

FIGURA 3. Injerto tallado.

En las estenosis de localización bulbar, el injerto fue colocado en posición ventral, con espongioplastia y cubierto por el músculo bulboesponjoso. Y en las estenosis panuretrales, se dividió el injerto colocándolo ventralmente en la porción bulbar y dorsal-

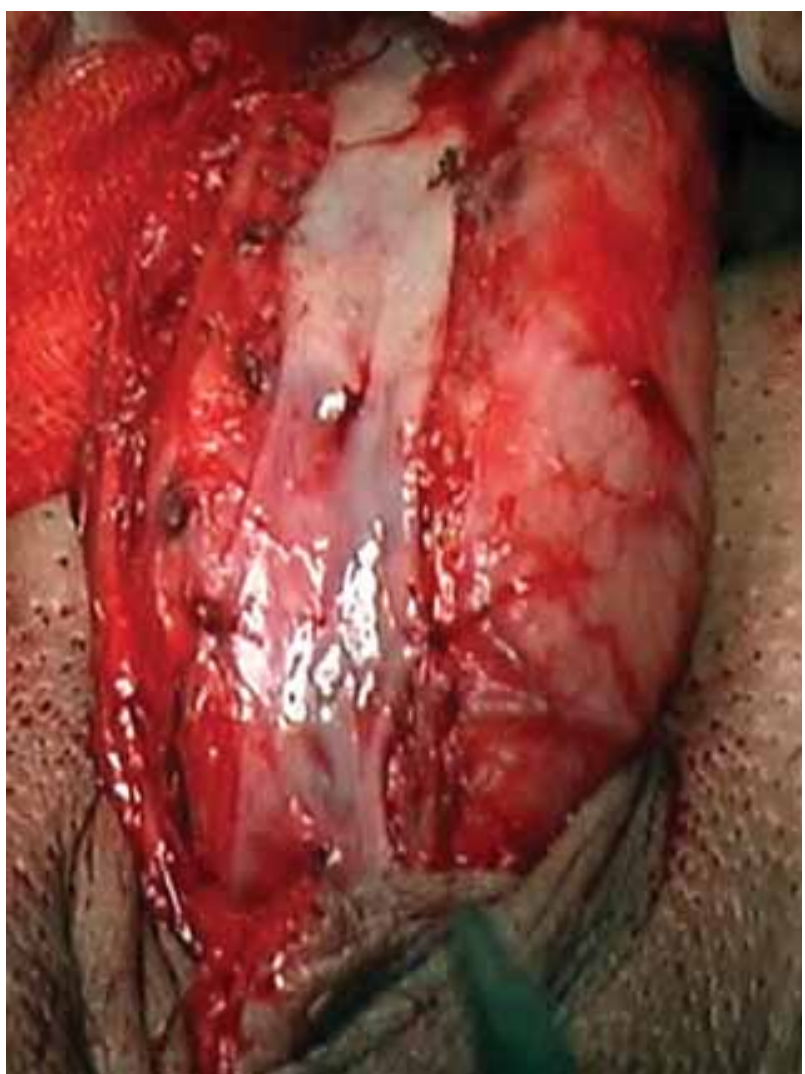

FIGURA 4. Colocación del injerto.

mente en la uretra péndula. En un caso de estenosis panuretral al que se había practicado previamente meatotomía ventral, se realizó reconstrucción del meato con injerto de mucosa bucal sobre incisión de placa uretral según técnica de Snodgrass. El injerto se unió a la uretra en sutura continua con poliglactina de 4/0 (Figs. 5 y 6). A todos los pacientes se les dejó catéter uretral durante 3 semanas realizando uretrografía miccional con sonda para comprobar la ausencia de fugas antes de la retirada del catéter (Tabla 1).

Inicialmente se solicitaba uretrografía miccional a los dos meses de la cirugía sustituyéndolo posteriormente por flujometría y evaluación de la satisfacción del paciente. En dos casos se realizó uretroscopia.

\section{RESULTADOS}

En la uretrografía miccional efectuada en el periodo postoperatorio precoz, con sonda, no se objetivó ninguna fuga, por lo que la sonda fue retirada a las tres semanas de la cirugía en todos los casos. En el primer caso se realizaron en el posto- 


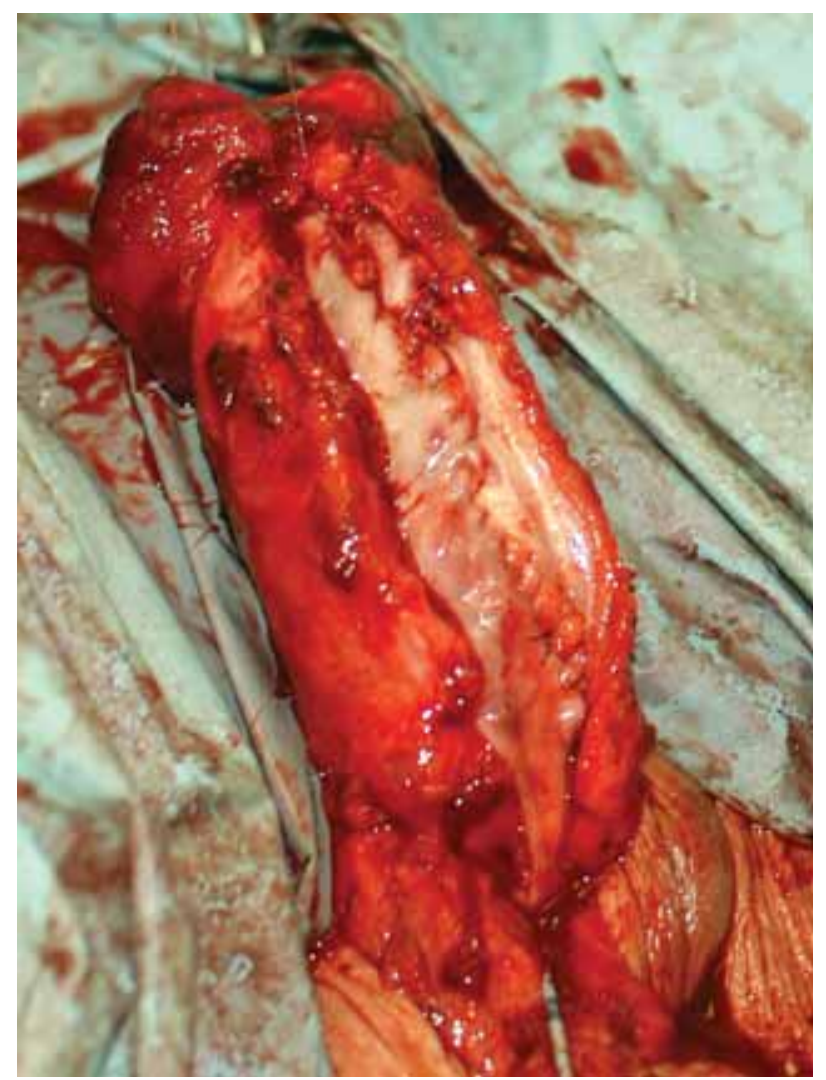

FIGURA 5. Uretroplastia

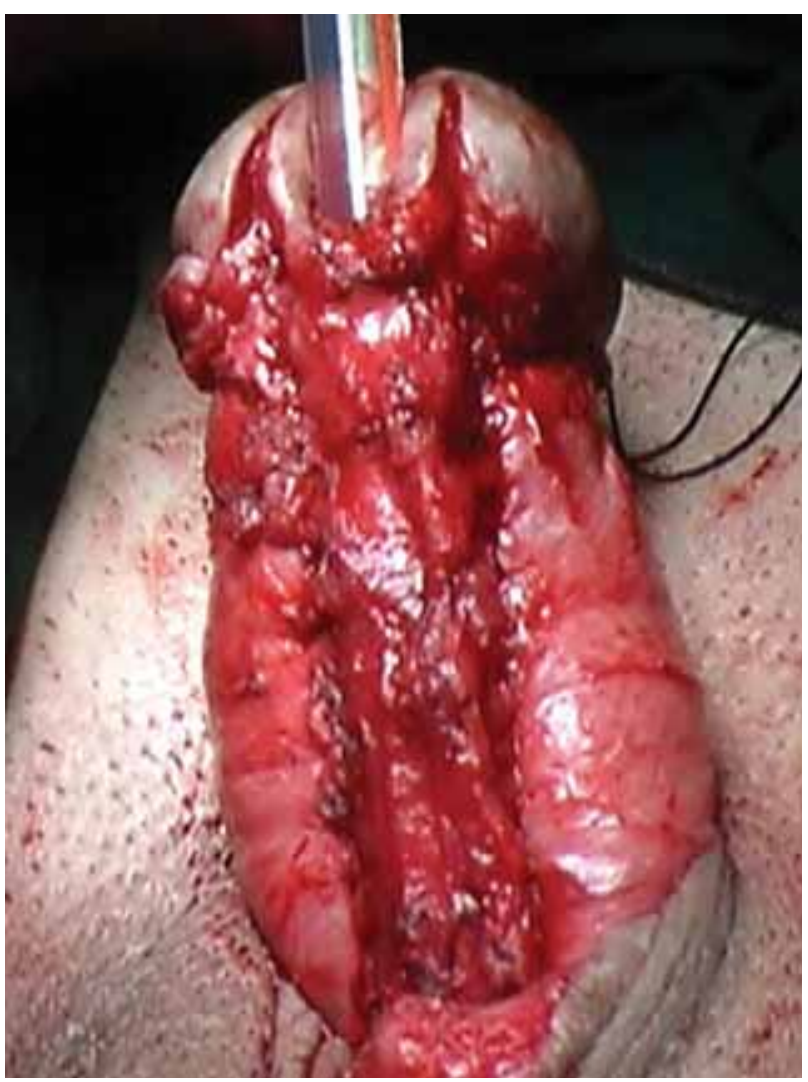

FIGURA 6. Uretroplastia

Tabla 1

\begin{tabular}{|c|c|c|c|c|c|c|c|c|c|c|}
\hline & Edad & Etiologia & Localización & Longitud & Uretrografia & Fecha IQ & $\begin{array}{l}\text { Longitud } \\
\text { Injerto }\end{array}$ & $\begin{array}{l}\text { Obtención } \\
\text { Injerto }\end{array}$ & $\begin{array}{c}\text { Localizacón } \\
\text { Injerto }\end{array}$ & $\begin{array}{c}\text { Seguimiento } \\
\text { (meses) }\end{array}$ \\
\hline Caso 1 & 68 & Deconocida & Péndula & $6 \mathrm{~cm}$ & $\mathrm{Si}$ & 5 febrero 2002 & $7 \mathrm{~cm}$ & Labio inferior & Dorsal & 62 \\
\hline Caso 2 & 47 & Traumática & Bulbar & $10 \mathrm{~cm}$ & $\mathrm{Si}$ & 10 junio 2002 & $10 \mathrm{~cm}$ & Labio inferior & Ventral & 58 \\
\hline Caso 3 & 50 & Desconocida & Bulbar & $5 \mathrm{~cm}$ & $\mathrm{Si}$ & 8 julio 2002 & $5 \mathrm{~cm}$ & Labio inferior & Ventral & 57 \\
\hline Caso 4 & 65 & Infecciosa? & Péndula & $5 \mathrm{~cm}$ & $\mathrm{Si}$ & 21 octubre 2002 & $6 \mathrm{~cm}$ & Labio inferior & Dorsal & 54 \\
\hline Caso 5 & 72 & Post- RTU & Péndula & $5 \mathrm{~cm}$ & $\mathrm{Si}$ & 20 noviembre 2002 & $6 \mathrm{~cm}$ & Labio inferior & Dorsal & 53 \\
\hline Caso 6 & 65 & Traumática & Panuretral & $14 \mathrm{~cm}$ & $\mathrm{Si}$ & 14 mayo 2003 & $14 \mathrm{~cm}$ & $\begin{array}{l}\text { Labio inferior } \\
\text { y mejillas }\end{array}$ & $\begin{array}{l}\text { Ventral en bulbar } \\
\text { y dorsal en péndula }\end{array}$ & 35 \\
\hline Caso 7 & 63 & Desconocida & Panuretral & $16 \mathrm{~cm}$ & $\mathrm{Si}$ & 5 junio 2003 & $16 \mathrm{~cm}$ & $\begin{array}{l}\text { Labio inferior y } \\
\text { mejillas }\end{array}$ & $\begin{array}{l}\text { Ventral en bulbar } \\
\text { y dorsal en péndula }\end{array}$ & 36 \\
\hline Caso 8 & 62 & Desconocida & Panuretral & $16 \mathrm{~cm}$ & $\mathrm{Si}$ & 23 julio 2004 & $16 \mathrm{~cm}$ & $\begin{array}{l}\text { Labio inferior } \\
\text { y mejillasr }\end{array}$ & $\begin{array}{c}\text { Ventral en bulba } \\
\text { y dorsal en péndula }\end{array}$ & 32 \\
\hline
\end{tabular}

peratorio tardío uretrografía retrógrada y miccional y uretroscopia, siendo ambas normales. Al segundo paciente se le hizo uretrografía retrógrada y miccional a los dos meses de la cirugía, siendo también normal. En los demás casos se ha llevado a cabo únicamente flujometría y evaluación de la satisfacción del paciente, objetivándose flujos por encima de $18 \mathrm{ml} / \mathrm{seg}$. en todos los casos y todos los pacien- tes se muestran subjetivamente satisfechos con el resultado de la cirugía.

Ninguno de los pacientes presentó complicaciones durante el postoperatorio precoz y tan sólo un paciente fue valorado por presentar dificultad miccional durante el postoperatorio tardío. Este paciente había sido portador de un catéter suprapúbico durante los 6 meses previos a la cirugía. 
Se practicó uretroscopia, objetivando una uretra de calibre normal sin estenosis. Este paciente presentaba dos cálculos vesicales grandes que se extrajeron mediante cistolitotomía, y desde entonces ha estado asintomático.

Con respecto a la zona de obtención del injerto, tan solo un paciente refirió parestesias en labio inferior que desaparecieron a los 6 meses de la cirugía.

Dos pacientes fallecieron a los 35 y 36 meses de la cirugía, de cáncer de pulmón y adenocarcinoma de colon con metástasis a distancia, respectivamente, asintomáticos desde el punto de vista urológico. El resto de pacientes continúan libres de recurrencia en la actualidad.

\section{DISCUSIÓN}

Cuando la longitud de la estenosis impide la escisión y anastomosis primaria, se ha de recurrir a tejidos interpuestos de otro origen. Las técnicas de injerto se consideran en la actualidad la primera elección en estos casos. La mucosa oral presenta importantes ventajas sobre los injertos cutáneos, ya que tiene unas características vasculares más óptimas debido a su plexo panlaminar y puede ser adelgazado sin dañarlas siempre que se conserve una porción de lámina propia suficiente en el injerto, además, se cree que su superficie epitelial húmeda le confiere características favorables para la reconstrucción uretral.

Existen varios factores que influyen en los resultados de este tipo de técnicas: localización y longitud de la estenosis, etiología, edad del paciente, antecedentes quirúrgicos en la zona, presencia de espongiofibrosis ${ }^{1}$.

El uso de mucosa bucal en la uretroplastia del adulto fue comunicada por primera vez por ElKasaby et al. ${ }^{2}$. Muchos han sido los autores que han comunicado sus series con posterioridad, señalando que la uretroplastia con mucosa bucal ofrece unos resultados comparables a la piel a corto-medio plazo, requiriéndose estudios a largo plazo ${ }^{3,4}$.

En referencia a la localización del injerto, en aquellos casos en que la estenosis incluya la uretra péndula, no hay duda que la situación ha de ser dorsal, sobre los cuerpos cavernosos, lo cual disminuye los problemas de saculación y pérdida del injerto $^{5}$, ya que el cuerpo esponjoso a este nivel es de menor grosor y por tanto menos vascularizado. Además, la fijación de la mucosa bucal a los cuerpos cavernosos mediante alguna sutura dispersa por el injerto, disminuye la retracción del mismo.
En otra situación nos encontramos cuando se habla de uretra bulbar. Hasta ahora, la localización del injerto ventralmente ha sido defendida por varios autores, debido a que constituye una técnica más fácil, en que se requiere menos disección y movilización de la uretra ${ }^{6}$. Recientemente, Barbagli et al. publican una serie de 50 pacientes en que los resultados de la uretroplastia bulbar no se ven afectados en función de la localización ventral, dorsal o lateral del injerto ${ }^{7}$.

El postoperatorio en estos pacientes es bueno y son dados de alta en pocos días con catéter uretral. Una de las complicaciones que se pueden observar de forma temprana es la presencia de una fístula que normalmente se suele resolver prolongando el tiempo de cateterismo vesical. Una de las complicaciones más importantes y que suele aparecer de forma más tardía es la recurrencia de la estenosis. Esta se puede desarrollar a pesar de una técnica quirúrgica y una elección del injerto adecuados. La recurrencia de la estenosis se puede presentar de dos formas: un tejido fibroso extenso que envuelve todo el área del injerto o anillos estenóticos cortos en la zona de la anastomosis proximal o distal. Varios autores han descrito estos anillos fibrosos en la zona de las anastomosis como causa del fallo de la uretroplastia ${ }^{8,9}$. Elliot et al sugieren que el fallo del injerto en la anastomosis distal se debe a que el grosor del cuerpo esponjoso a este nivel es menos vascular lo que representa una inosculación del injerto más pobre debido a que el lecho del injerto está menos vascularizado. Los mismos autores atribuyen la presencia de un anillo proximal a un subestadiaje de la estenosis durante la cirugía, enfatizando en la importancia de una incisión de la uretra hasta tejido sano para una completa incisión de la estenosis ${ }^{7}$. Sin embargo, Barbagli et al. sugieren que la aparición de estos anillos de estenosis es debida a la retracción que tienen los injertos, la cual es mayor en los sitios donde el injerto es más estrecho, la zona de la anastomosis. También sugieren que el tipo de orientación lineal de la sutura puede tener importancia en este aspecto, así como la disminución del material de sutura entre el injerto y el lecho ${ }^{9,10}$. El tratamiento para estas recidivas en anillo puede ser mínimamente invasivo, como las dilataciones o uretrotomía interna.

En cuanto a la obtención del injerto de mucosa bucal, su manejo y morbilidad, hay menos datos y opiniones publicados. Algunos autores recomiendan 
tallar el injerto a partir de la mucosa de la zona interna de la mejilla en vez de en labio inferior, ya que esta zona es más amplia y más consistente, disminuyendo la saculación que se produce en el injerto colocado ventralmente cuando no se puede realizar espongioplastia ${ }^{11}$. En cuanto a la morbilidad, la región alrededor del foramen mentoniano, donde dicho nervio abandona la mandíbula, es un punto de máximo riesgo ya que su lesión produce un daño irreversible que se traduce a nivel clínico en parestesias y entumecimiento o parálisis del labio inferior. Sin embargo la zona de riesgo cuando el injerto se toma de la parte interna de la mejilla, es el daño del conducto de Stenon. Su lesión puede provocar la inflamación de la glándula parótida o la formación de quistes mucosos ${ }^{11,12}$. Tolstunov et al. en una serie de 12 pacientes encuentran que el 75\% presentan una disminución temporal del flujo de saliva del conducto de Stenon ipsilateral que se resuelve en una semana de la intervención. Lo atribuyen al edema postoperatorio que se produce alrededor de la porción terminal del conducto y de la papila. Estos autores comentan que para prevenir el daño del conducto la disección del injerto se ha de mantener a $8 \mathrm{~mm}$ de la papila $\mathrm{y}$ que se ha de tener cuidado al suturar la zona para no incluir la papila o el conducto en la sutu$\mathrm{ra}^{13}$. Por todo ello se recomienda tallar el injerto a partir de la mucosa de la parte interna de la mejilla y reservar el labio inferior para aquellos pacientes con estenosis mayores de $15 \mathrm{~cm}$, donde, la mucosa de las mejillas no será de suficiente longitud. Cuando el uso del labio interior se haga inevitable, se ha poner mucho cuidado en no dañar el nervio mentoniano ni ninguna de sus ramas. Se recomienda no usar la electrocoagulación en esta zona, realizando la hemostasia mediante compresión (dejando una gasa empapada durante 3 horas después de la cirugía) y no suturar la zona para evitar retracciones del labio ${ }^{11,12}$. Nosotros tallamos los injertos del labio inferior y solo hemos utilizado la parte interna de las mejillas en los casos en que por la longitud de la estenosis necesitábamos un injerto más largo. Aunque no hemos tenido las complicaciones comentadas por estos autores en la serie que presentamos, probablemente en la actualidad utilizaríamos de preferencia la mucosa de la cara interna de la mejilla. Si no lo hicimos en ese momento fue porque nos preocupaba la lesión del conducto de Stenon. Pero después de utilizar mucosa de ambas mejillas y labio inferior en estenosis largas, hemos de reconocer que la mucosa del labio inferior es más frágil y más difícil de tallar el injerto, aparte del riesgo de lesión del nervio mentoniano.

En cualquier caso, tanto en mucosa del labio inferior como con la de las mejillas, los resultados son ilusionantes.

\section{REFERENCIAS}

1. Berger B, Sykes Z, Freedman M. Patch graft urethroplasty for urethral stricture disease. J Urol. 1976;115(6):681-684.

2. El-Kasaby A.W, Fath-Alla M, Noweir A.M, El-Halaby MR, Zakaria W, El-Beialy MH. The use of buccal mucosa patch in the management of anterior urethral strictures. J Urol. 1993; 149(2):276-278.

3. Grady JD, McCammon K, Schlosseberg SM. Buccal mucosa graft for penile urethral strictures. J Urol 1999; 161: 375A.

4. Gupta N.P, Ansari M.A, Dogra P.N, Tandon S. Dorsal buccal graft urethroplasty by a ventral sagittal urethrotomy and minimal-access perineal approach for anterior urethral stricture. BJU Int. 2004;93(9):1287-1290.

5. Wessells H, McAninch JW. Use of free grafts in urethral stricture reconstruction. J Urol. 1996;155(6):1912-1915.

6. Wessells $\mathrm{H}$. Ventral onlay graft techniques for urethroplasty. Urol Clin N Am. 2002;29(2):381-387.

7. Barbagli G, Palminteri E, Guazzoni G, Montorsi F, Turini D, Lazzeri M. Bulbar urethroplasty using bucal mucosa grafos placed on the ventral, dorsal o lateral surface of the uretra: are results affeted by the surgical technique?. J Urol. 2005;174(3): 955-957.

8. Elliot SP, Metro MJ, McAninch JW. Long-term followup of the ventrally placed buccal mucosa onlay graft in bulbar urethral reconstruction.. J Urol. 2003 May;169(5):1754-1757.

9. Barbagli G, Guazzoni G, Palminteri E, Lazzeri M. Anastomotic fibrous ring as cause of stricture recurrence after bulbar onlay graft urethroplasty. J Urol. 2006;176(2):614-619.

10. Bach AD, Bannasch H, Galla TJ, Bittner KM, Stark GB. Fibrin glue as matrix for cultured autologus urothelial cells in urethral reconstruction. Tissue Eng. 2001;7(1):45-53.

11. Eppley B.L, Keating M, Rink R. A buccal mucosal harvesting technique for urethral reconstruction. J Urol. 1997;157(4): 12681270 .

12. Alantar A, Roche Y, Maman L Carpentier P. The lower labial branches of the mental nerve: anatomic variations and surgical relevance. J Oral Maxillofac Surg. 2000;58(4):415-418.

13. Tolstunov L, Pogrel M.A, McAninch J.W. Intraoral morbidity following free buccal mucosal graft harvesting for urethtoplasty. Surg Oral Med Oral Pathol Oral Radiol Endod. 1997;84 (5): $480-82$.

Correspondencia autor: Dr. A. Roca Edreira

Hospital Univ. Marqués de Valdecilla

Avda. Valdecilla, s/n - 39008 Santander (Cantabria)

Tel.: 942202520

E-mail autor: anroed@ono.es

Información artículo: Original - Uretroplastia

Trabajo recibido: julio 2007

Trabajo aceptado: noviembre 2007 